\title{
Libido Decreased, CTCAE
}

National Cancer Institute

\section{Source}

National Cancer Institute. Libido Decreased, CT CAE. NCI Thesaurus. Code C143649.

A disorder characterized by a decrease in sexual desire. 